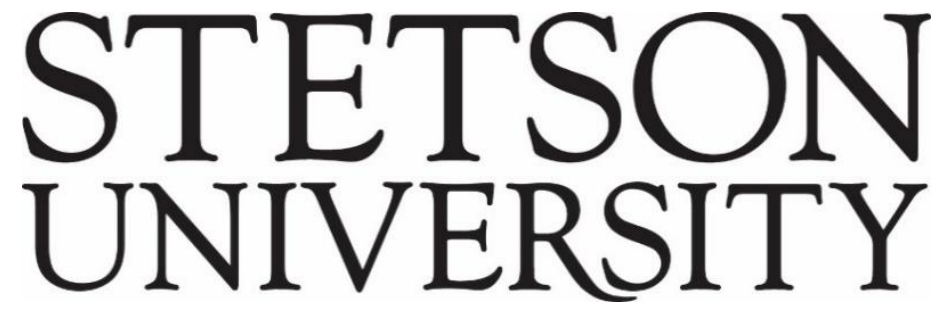

Voices of Reform: Educational Research to Inform and Reform

Volume $3 \bullet$ Issue $2 \bullet$ Article 3

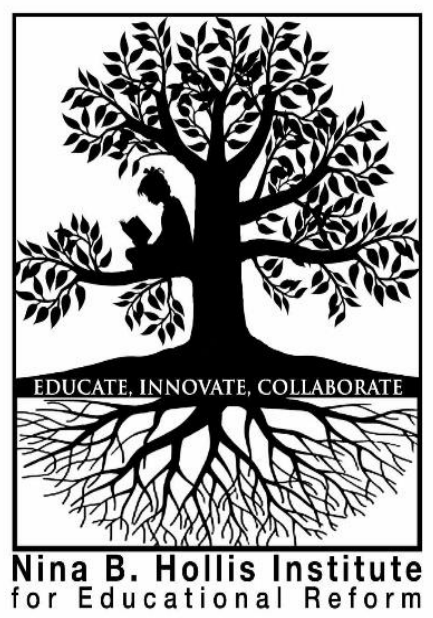

December 2020

\title{
Misunderstood and Mistreated: Students of Color in Special Education
}

Hani Morgan

University of Southern Mississippi

Follow this and additional works at: http://www.voicesofreform.com

Recommended Citation

Morgan, H. (2020). Misunderstood and mistreated: Students of color in special education. Voices of Reform, 3(2), 71-81. Retrieved from https://www.voicesofreform.com/article/18595-misunderstood-and-mistreated-students-ofcolor-in-special-education doi: 10.32623/3.100005

http://dx.doi.org/10.32623.3.10005

Revisions

Submission date: February $17^{\text {th }}, 2020$

$1^{\text {st }}$ Revision: April $28^{\text {th }}, 2020$

Acceptance: May $11^{\text {th }}, 2020$

Publication date: December 29 ${ }^{\text {th }}, 2020$ 


\title{
Misunderstood and mistreated: Students of color in special education
}

\author{
Hani Morgan ${ }^{1}$ \\ ${ }^{1}$ School of Education \\ University of Southern Mississippi, United States \\ hani.morgan@usm.edu
}

\begin{abstract}
The disproportionate representation of students of color in special education is a serious concern that has lasted for forty years. Research suggests that students of color are too often not identified accurately for special education and that the programs they are placed in are frequently poor in quality. This trend contributes to a less-than-optimal learning environment that lowers their chances for future success. Some of the factors that may contribute to this problem include poverty and inaccurate teacher perceptions. To reduce this problem, teachers can be trained to be culturally responsive and the public-school system can be improved so that students from low-income households receive better services.
\end{abstract}

\section{Keywords}

special education, poverty, equity, social justice in education

\section{Misunderstood and Mistreated: Students of Color in Special Education}

The disproportionate representation of students of color in special education has been a concern about the education of students from low-income families for many years. Low-income students are more often identified in subjective disability categories, such as emotional disability and intellectual disability, and more frequently placed in separate classrooms. Further, after being identified in this manner, these pupils tend to be placed in classrooms where academic outcomes are worse, expectations for success are lower, and the stigma associated with special education is higher (Schifter, Grindal, Schwartz, \& Hehir, 2019). They are also frequently placed in classrooms with teachers who have less expertise in math, English, and science. These circumstances have raised concerns about systemic racial bias because low-income children are more likely to be students of color (Tatter, 2019).

Additionally, research shows that when students of color need special services in certain areas, they often do not receive them. For example, Morgan and Farkas (2018) found that 74\% of White 
fourth-grade children with reading difficulties were receiving special education services but that only $44 \%$ of Black children and $43 \%$ of Hispanic children were receiving them.

\section{Concerns About Special Education Placement}

Although placement in special education is designed to help students, it can reduce their employment options and opportunities for higher education (Bal, Sullivan, \& Harper, 2014). The outcomes associated with placement in ineffective special education programs also include exposure to an environment that leads to more severe and frequent disciplinary action (Camera, 2017) that may result in fewer learning opportunities (Cooc, 2017). On the other hand, failing to provide special services to students who need them prevents pupils who have historically been underserved from gaining access to the programs that will help them succeed academically (Morgan \& Farkas, 2018).

Although placing students in special education has been found to benefit students with mild disabilities, it is frequently viewed as ineffective for many pupils, contributing to consequences that outweigh the advantages of receiving additional services (Dever, Raines, Dowdy, \& Hostutler, 2016). Since students of color already experience inequalities in schools at a high rate, the negative outcomes associated with their placement in special education are serious. These outcomes include racial segregation, stigmatization, and group misrepresentation (Skiba, Artiles, Kozleski, Losen, \& Harry, 2016).

Unfortunately, certain groups of students are placed in specific special education categories at alarmingly high rates. For instance, the U.S. Department of Education (2015) indicated that African American students ages 6 through 21 were over two times more likely to receive services for emotional disturbance and intellectual disabilities than were students from all other racial/ethnic groups. Ford and Russo (2016) indicated that Black students are over-referred and over-identified in subjective special education placement areas more than any other group.

\section{Definition of Disproportionate Identification}

Disproportionate identification generally refers to group differences in the rate at which one group is assigned to a category at a higher or lower rate than that of students from other groups (Sullivan \& Osher, 2019). Conversely, proportionate representation occurs when students of one race/ethnicity are assigned to a category at the same rate as students from other groups are. Overrepresentation takes place when a group is represented at a higher rate in a category than the rate at which other populations are represented, and underrepresentation occurs when a group is represented at a lower rate (Robinson \& Norton, 2019).

One of the methods for determining if a given group is overrepresented is the composition index. This method involves comparing the ratio of pupils from a particular demographic group identified for special education with the ratio of pupils of the same group within all of the student population (Counts, Katsiyannis, \& Whitford, 2018). 


\section{Background}

Research on disproportionate group differences in special education identification has to a great extent focused on the overrepresentation of Black students. Various studies have investigated differences in identification of intellectual disability, emotional disturbance, and learning disability. Although there is a lack of consensus about the reasons for disproportionality, most scholars agree that disproportionate representation can be caused by misidentification (Sullivan \& Osher, 2019).

Previous reports have revealed that the persistent and substantial overrepresentation of Black students in special education has lasted for forty years (Ford \& Russo, 2016) and that the use of biased methods of identifying these students likely contributes to this outcome (Bean, 2013). Other minority groups, such as Native Americans, have been found to be overrepresented in special education as well (Cooc, 2017; Dever et al., 2016). The overrepresentation of a particular group can manifest itself in several ways:

- Culturally and linguistically diverse (CLD) students can be over-identified for special education at the national, state, and district levels.

- CLD students can receive special education services at higher rates in more segregated or restrictive programs.

- They can be overrepresented in specific special education categories, such as emotional disturbance and intellectual disabilities.

- They can experience disciplinary actions, such as suspensions and expulsions, at higher rates than other students.

Although the disproportionate representation of African American students in special education was initially identified as a problem in the 1960s, the roots of this concern date back to a much earlier period. Before the 1950s, the dominant view toward this group involved educating them not for equal citizenship, but for lower ranked positions they would hold (Skiba et al., 2008).

Regrettably, even after the Brown vs. Board of Education (1954) decision, some educational practices, such as placing students in special education and sorting them by ability, separated minority students from others. In the 1960s and 1970s, court challenges occurred, contesting that discriminatory educational practices that led to the racial isolation of minority students were a violation of the Equal Protection Clause of the Constitution and Title VI of the Civil Rights Act of 1964.

Although concerns about discriminatory practices led to research in the 1970s and 1980s, these early studies did not reveal insights on the mechanisms that promote racial differences in the identification of students in special education. In later years, research focused more on the factors leading to this problem (Skiba et al., 2008). 


\section{Factors Related to Disproportionality}

Cooc (2017) discussed several research areas that focus on the factors contributing to the disproportionate identification of certain groups in special education. The first is based on the hypothesis that disproportionality occurs because certain groups of minority students are more likely to experience adverse conditions as a result of living in poverty. These conditions lead to health problems that affect learning and special education referrals.

The second area focuses on racial biases. For example, assessments might be culturally inappropriate. In addition, teachers may have biased perceptions that influence them to refer more students from one racial group in special education than those from another although students from both groups display the same condition.

The third area emphasizes the sociohistorical context. Researchers focusing on this topic examine whether school decisions reflect historical assumptions about race that disadvantage minority students regarding disability decisions.

\section{Poverty}

Living in poverty is associated with conditions that make academic success difficult. For example, low-income children suffer from vision impairment at twice the normal rate. They endure this condition as a result of the poor prenatal development that occurs when low-income pregnant mothers do not get adequate care and nutrition (Morgan, 2019). Unfortunately, Black, Hispanic, and Native American students live in poverty at much higher rates than White families (Morgan, 2018a; Sauter, 2018).

Researchers have hypothesized that living in poverty contributes to the disproportionate rate of students of color in special education since these students are more likely to be exposed to risk factors that increase academic underachievement and behavioral problems. In addition to vision impairment, low-income students suffer more from the effects of exposure to lead, high blood pressure, and low birth weight (Morgan \& Farkas, 2018).

\section{Teacher Perception}

One of the most important factors within the school system that can contribute to racial disparities in referrals for special education is the teacher's role in the process of identifying students. Indeed, the identification of students for special education starts with a teacher's belief concerning whether or not a student has a disability (Cooc, 2017). Unfortunately, teachers sometimes hold biased views toward students from cultural minority groups.

Although teachers of the same race as their students are more likely to be aware of the cultural characteristics of their pupils, there is a lack of teachers of color in public schools (Morgan, 2019). Scholars have therefore hypothesized that many students of color are perceived to have disorders as a result of not understanding aspects of students' cultures (Bean, 2013). For instance, Rudd (2014) mentioned a study that revealed that teachers perceived students who displayed a walking style more commonly used by Black adolescents as in more need of special education services. 
Other studies support the view that teachers hold biased perceptions toward students of color. One of these involved a sample of 57 female teachers, most of whom were White. This research explored how teachers would react to misbehavior. Although the researchers found that the teachers, who represented all grade levels from across the country, did not respond stereotypically after a student's first infraction, they were more likely to stereotype Black students as troublemakers after a second infraction (Weir, 2016).

Another study focused on the beliefs high school teachers held toward students' academic potential by investigating whether non-Black teachers had biased expectations of Black students. Gershenson, Holt, and Papageorge (2016) found that non-Black teachers had significantly lower expectations than Black teachers and that non-Black teachers were less likely to believe that Black students would complete a four-year college degree. They concluded that their study provided evidence for the need to hire a more diverse and representative teaching force.

Cherng's (2017) study indicated that English teachers underestimate the academic abilities of Black students and other students of color and that math teachers hold similar perceptions of these students. His study revealed that teachers' underestimation of students' academic ability in the $10^{\text {th }}$ grade is linked to lower $12^{\text {th }}$ grade expectations. He concluded from his research that teacher perceptions may be racially biased and that these biases are associated with lower student expectations and achievement. His findings are consistent with the belief that low expectations are harmful to students' self-conception and are associated with poorer academic outcomes.

Ouazad (2014) focused on teachers of younger students to explore if they assess same-race students more favorably. The results of his study showed that teachers of students from kindergarten to grade 5 assess same-race students more favorably and that the effects of this treatment persist in later years. He also noted that the K-5 years were an important period in the education of children since academic racial gaps occur rapidly during these years.

Another study involving the analysis of longitudinal data on all public-school students in North Carolina showed that Black students benefit from having teachers of the same race. This research indicated that students were less likely to drop out of high school and more likely to plan on going to college when assigned to a Black teacher at least once in the third, fourth, or fifth grades. In addition, the researchers mentioned that the dropout effect was greatest among Black boys who experienced persistent poverty during their years in primary school. They also pointed out that future research is needed to better understand how much of an impact Black teachers with higher expectations may make. Their findings support implementing a policy that encourages assigning Black male students to Black teachers to close achievement gaps (Gershenson, Hart, Lindsay, \& Papageorge, 2017).

Teacher perceptions are important because they may not only contribute to the disproportionate identification of students of color in special education but also prevent students with learning disabilities from getting the education they deserve after they are identified. These outcomes could occur as a result of the lower expectations teachers may hold for the behavior and achievement of students of color. Although special education placement can provide critical services that lead to 
academic success, it can also result in low teacher expectations that prevent students from performing well in school (Schifter, Grindal, Schwartz, \& Hehir, 2019).

\section{Sociohistorical Context}

In 1975, the Education for All Handicapped Children Act (EAHCA), now the Individuals with Disabilities Education Act (IDEA), was enacted. This legislation addressed the needs of students with disabilities. Although IDEA was created to provide equity, policymakers did not think carefully about the cultural-historical factors that may lead it to be misaligned with the Brown vs. Board of Education (1954) decision. Although the Brown decision declared that racial segregation was unconstitutional, after the passage of IDEA, an increase in the rate of students of color placed in special education occurred. Unfortunately, the mandatory desegregation of schools dismantled the relationships among African American schools, African American parents, and African American communities. This outcome reduced parents' ability to fight the disproportionate placement of their children in programs for students with certain disabilities (Artiles, Kozleski, Trent, Osher, \& Ortiz, 2010).

The inequalities resulting from the disproportionate placement of students of color in special education are unfortunate because IDEA was designed to increase the rights of students with disabilities. The history of special education before and after the passage of IDEA reveals that this policy was meant to encourage equity. Before the enactment of IDEA, a few states passed laws designed to protect the rights of students with special needs. However, after IDEA was enacted, all students were provided with this protection, and the mandate required six major principles to be followed to ensure that all children with special needs would receive specialized services. These principles involved a zero reject model, an individualized education program, nondiscriminatory evaluation, education in the least restrictive environment, procedural due process for parents and schools, and parental and student participation (if appropriate) in all aspects of the special education process (Artiles et al., 2010).

\section{The Impact of the Problem}

In addition to the concerns previously mentioned about the harmful effects associated with the disproportionate representation of students of color in special education are other reasons educators need to be aware of to reduce this problem. For example, assigning a disproportionate rate of students from a given racial group to segregated classrooms is harmful because inclusive educational settings benefit students with disabilities in many ways. The advantages associated with inclusive settings include fewer behavioral problems, improved math and reading achievement, higher graduation rates, improved attendance, and lower rates of unemployment after graduation (Potter \& Quick, 2018).

In addition, in most cases, non-disabled students do not experience negative consequences when they are educated with students with disabilities and can even benefit from this practice (Hehir et al., 2016). When educated alongside peers with disabilities, students without disabilities usually exhibit reduced prejudice and increased self-esteem (Potter \& Quick, 2018). 
In order for students of color to benefit from special education, they need to be identified accurately and placed in effective programs. In too many cases, placing these students in special education leads to less-than-optimal results. For example, a study on over 1,000 children who were predominantly African American revealed that those receiving special education services tended to experience lower rates of high school completion and higher rates of depression, incarceration, and substance misuse.

The researchers offered several explanations for these outcomes. They mentioned that schools may use effective research-based practices infrequently and that the label of special education may harm children psychologically and also lead to stigmatization, bullying, and low teacher expectations (Chesmore, Ou, \& Reynolds, 2016). They also reported that previous studies revealed that students placed in special education were at greater risk of dropping out of high school, earning less, experiencing unemployment, and enrolling in postsecondary education for fewer years.

\section{Strategies for Reducing the Problem}

One way to alleviate the problems associated with the special education programs students of color are often placed in is to train teachers to be culturally responsive. Ford and Russo (2016) suggested implementing this approach to deal with the lack of college courses that focus on preparing educators for teaching these students. Another reason this training is crucial is that there is a lack of teachers of color in the public-school system. As previously noted, teachers of the same race as their students are more likely to be aware of the cultural characteristics of their students than teachers of a different race. Increasing the cultural competence of educators can be achieved by offering professional development sessions:

[T]here is work indicating that when such preparation is evident, educators are less biased in their views of Black and other students of color. In other words, culturally competent educators are more likely to see strengths in their students. This can decrease special education (over) referrals. Accordingly, educational leaders should offer regular, annual professional development sessions with teachers and other staff to explain the importance of being culturally responsive. (Ford \& Russo, 2016, p. 56)

Training educators to be culturally responsive will help them recognize the cultural characteristics of African American and other students of color. For example, Ford (2012) discussed nine characteristics of African American students that teachers need to be aware of to avoid misunderstandings. Each characteristic reflects the way many of them behave in school. For instance, these students' sense of harmony involves recognition of the connection between people and their environment. This characteristic often leads them to be more sensitive to nonverbal and situational messages. Black students may also show a sense of working cooperatively. However, teachers may misinterpret this style as a weakness. Educators need to be aware of these and other cultural characteristics to reduce misinterpretations that lead to referrals to special education.

Another strategy involves improving the inadequate schools many low-income students attend. Schools in low-income districts generally receive less funding than wealthier schools and operate 
with fewer resources (Morgan, 2018b, 2020). This condition contributes to an increase in undertrained teachers who have to take on larger workloads. As a consequence, teachers in lowincome schools are less likely to provide the time needed to work with students with special needs to make sure their needs are met (Koseki, 2017).

Involving students' families is also essential. Information sessions and parent workshops can be organized to explain various aspects of the IDEA. Family members need to know their rights as decision makers and the kinds of behavior and learning problems IDEA defines as disabilities. This information will allow them to make the best decisions, including those involving the refusal of special education placement (Ford \& Russo, 2016).

The inclusion of a mandatory school counselor will likely compensate for the limited influence many parents of low-income students with special needs have toward improving their children's educational opportunities. These parents typically have difficulty understanding the due-process materials schools use since these documents are written in legalese requiring college level schooling to understand (Morgan \& Farkas, 2018).

Low-income parents lack the financial resources to hire knowledgeable experts, preventing them to take advantage of IDEA's reliance on parental advocacy. A counselor can serve as an advocate and can play a similar role as the one that a parent from a wealthier family might play. Congress can improve the opportunities for low-income students with special needs by requiring school counselors to speak for low-income students' unique needs (Koseki, 2017).

\section{Conclusion}

The disproportionate representation of students of color in special education is a serious and controversial concern that needs to be dealt with well. This problem is controversial because overrepresentation in special education does not necessarily mean that students from a given group are placed inappropriately. In fact, Morgan and Farkas (2018) argue that students of color are frequently under-identified for special services. Nonetheless, evidence exists suggesting that bias occurs in the placement of these students, that they are more likely to be segregated than other students, and that the programs they attend are inferior in quality. If children are in need of special education, it would be tragic to not provide it. However, inappropriate placement in segregated programs that will likely not yield favorable outcomes is tragic as well. Unfortunately, research suggests that these trends occur too often.

To alleviate this problem, policymakers need to lower the chances of biased placement and reduce the rate at which students of color are segregated when placed in special education. They also need to improve the overall quality of the educational services these children receive and to provide special services to all students who need them. To avoid biased placement, schools need to implement policies that increase culturally responsive practices. These policies need to focus on providing training to increase cultural competence and ensuring that committees of decision makers are racially diverse (Ford \& Russo, 2016).

Finally, the unacceptable practice of funding high-poverty schools inadequately needs to end. Students who attend low-income schools need more support from qualified educators, not less. 
Using the aforementioned strategies will prevent the inappropriate placement of students of color in special education and will increase their opportunities for receiving it when they need it.

\section{References}

Artiles, A. J., Kozleski, E. B., Trent, S. C., Osher, D., \& Ortiz, A. (2010). Justifying and explaining disproportionality, 1968-2008: A critique of underlying views of culture. Exceptional Children, 76(3), 279299.

Bal, A., Sullivan, A., \& Harper, J. (2014). A situated analysis of special education disproportionality for systemic transformation in an urban school district. Remedial and Special Education, 35(1), 3-14.

Bean, K. F. (2013). Disproportionality and acting-out behaviors among African American children in special education. Child \& Adolescent Social Work Journal, 30(6), 487-504.

Camera, L. (2017, August 31). New study questions links between race, disability in students. U.S. News \& World Report. Retrieved from https://www.usnews.com/news/education-news/articles/2017-08-31/new-studyquestions-links-between-race-disability-in-students

Cherng, H. S. (2017). If they think I can: Teacher bias and youth of color expectations and achievement. Social Science Research, 66, 170-186.

Chesmore, A. A., Ou, S. R., \& Reynolds, A. J. (2016). Childhood placement in special education and adult wellbeing. Journal of Special Education, 50(2), 109-120.

Cooc, N. (2017). Examining racial disparities in teacher perceptions of student disabilities. Teachers College Record, 119, 1-32.

Counts, J., Katsiyannis, A., \& Whitford, D. K. (2018). Culturally and linguistically diverse learners in special education: English learners. NASSP Bulletin, 102(1), 5-21.

Dever, B. V., Raines, T. C., Dowdy, E., \& Hostutler, C. (2016). Addressing disproportionality in special education using a universal screening approach. The Journal of Negro Education, 85(1), 59-71.

Ford, D. Y. (2012). Culturally different students in special education: Looking backward to move forward. Exceptional Children, 78(4), 391-405.

Ford, D. Y., \& Russo, C. J. (2016). Historical and legal overview of special education overrepresentation: Access and equity denied. Multiple Voices for Ethnically Diverse Exceptional Learners, 16(1), 50-57.

Gershenson, S., Hart, C. M. D., Lindsay, C. A., \& Papageorge, N. W. (2017). The long-run impacts of same-race teachers. Bonn, Germany: IZA - Institute of Labor Economics.

Gershenson, S., Holt, S. B., \& Papageorge, N. W. (2016). Who believes in me? The effect of student-teacher demographic match on teacher expectations. Economics of Education Review, 52, 209-224.

Hehir, T., Grindal, T., Freeman, B., Lamoreau, R., Borquaye, Y., \& Burke, S. (2016). A summary of the evidence on inclusive education. Cambridge, MA: Abt Associates.

Koseki, M. H. (2017). Meeting the needs of all students: Amending the idea to support special education students from low-income households. Fordham Urban Law Journal, 44(3), 793-832.

Morgan, H. (2018a). What every educator needs to know about America's homeless students. The Clearing House, $91(6), 215-221$.

Morgan, H. (2018b). The world's highest-scoring students: How their nations led them to excellence. New York, NY: Peter Lang Publishing.

Morgan, H. (2019). The lack of minority students in gifted education: Hiring more exemplary teachers of color can alleviate the problem. The Clearing House, 92(4-5), 156-162.

Morgan, H. (2020). Making America \#1 in education with three reforms. The Clearing House, 93(1), 5-11.

Morgan, P. L., \& Farkas, G. (2018, May 4). Are too many minority students identified as disabled? Or are some who need services overlooked? The Washington Post. Retrieved from https://www.washingtonpost.com/news/answer-sheet/wp/2018/05/04/are-too-many-minority-studentsidentified-as-disabled-or-are-some-who-need-services-overlooked/

Ouazad, A. (2014). Assessed by a teacher like me: Race and teacher assessments. Education Finance and Policy, 9(3), 334-72.

Potter, H., \& Quick, K. (2018). Preventing double segregation for students with disabilities. The Century Foundation. Retrieved from https://tcf.org/content/ commentary/preventing-double-segregation-studentsdisabilities/

Robinson, G. C., \& Norton, P. C. (2019). A decade of disproportionality: A state-level analysis of African American students enrolled in the primary disability category of speech or language impairment. Language, Speech, and Hearing Services in Schools, 50, 267-282. 
Rudd, T. (2014). Racial disproportionality in school discipline. Columbus, OH: Kirwan Institute for the Study of Race and Ethnicity.

Sauter, M. B. (2018, October 10). Faces of poverty: What racial, social groups are more likely to experience it? USA Today. Retrieved from https://www.usatoday.com/story/money/economy/2018/10/10/faces-poverty-socialracial-factors/37977173/

Schifter, L. A., Grindal, T., Schwartz, G., \& Hehir, T. (2019). Students from low-income families and special education. The Century Foundation. Retrieved from https://tcf.org/content/report/students-low-incomefamilies-special-education/?agreed $=1$

Skiba, R. J., Artiles, A. J., Kozleski, E. B., Losen, D. J., \& Harry, E. G. (2016). Risks and consequences of oversimplifying educational inequities: A response to Morgan et al. (2015). Educational Researcher, 45(3), 221-225.

Skiba, R. J., Simmons, A. B., Ritter, S., Gibb, A. C., Rausch, M. K., Cuadrado, J., \& Chung, C. G. (2008). Achieving equity in special education: History, status, and current challenges. Exceptional Children, 74(3), 264-288.

Sullivan, A. L., \& Osher, D. (2019). IDEA's double bind: A synthesis of disproportionality policy interpretations. Exceptional Children, 85(4), 395-412.

Tatter, G. (2019). Low-income students and a special education mismatch. Harvard Graduate School of Education. Retrieved from https://www.gse.harvard.edu/news/uk/19/02/low-income-students-and-special-educationmismatch

U. S. Department of Education (2015). 37th annual report to Congress on the implementation of the Individuals with Disabilities Education Act, 2015. Alexandria, VA: U.S. Department of Education.

Weir, K. (2016). Inequality at school: What's behind the racial disparity in our education system? American Psychological Association. Retrieved from https://www.apa.org/monitor/2016/11/cover-inequality-school 